\title{
Temporal and spatial analyses on seismo-electric anomalies associated with the 27 February $2010 M=8.8$ Chile earthquake observed by DEMETER satellite
}

\author{
Y.-Y. Ho ${ }^{1}$, J.-Y. Liu ${ }^{1,2,3}$, M. Parrot ${ }^{4}$, and J.-L. Pinçon ${ }^{4}$ \\ ${ }^{1}$ Institute of Space Science, National Central University, Jhongli, Taiwan \\ ${ }^{2}$ Center for Space and Remote Sensing Research, National Central University, Jhongli, Taiwan \\ ${ }^{3}$ National Space Origination, Hsin-Chu, Taiwan \\ ${ }^{4}$ LPC2E, CNRS, Orléans, France \\ Correspondence to: J. Y. Liu (jyliu@ jupiter.ss.ncu.edu.tw)
}

Received: 25 May 2012 - Published in Nat. Hazards Earth Syst. Sci. Discuss.: Revised: 24 June 2013 - Accepted: 1 July 2013 - Published: 16 December 2013

\begin{abstract}
This paper studies seismo-electromagnetic anomalies observed by the French satellite DEMETER (Detection of Electro-Magnetic Emissions Transmitted from Earthquake Regions) during the 27 February $2010 M=8.8$ Chile earthquake. The nighttime electron density $\left(N_{\mathrm{e}}\right)$, electron temperature $\left(T_{\mathrm{e}}\right)$, ion density $\left(N_{\mathrm{i}}\right)$, ion temperature $\left(T_{\mathrm{i}}\right)$ and whistler counts $\left(C_{\mathrm{w}}\right)$ are investigated. A statistical analysis of the box-and-whisker method is applied to see if data of two or more groups under study are significantly different. A cross-examination of temporal variations before and after shows that $N_{\mathrm{e}}$ and $N_{\mathrm{i}}\left(C_{\mathrm{w}}\right)$ increases (decreases) appear 10-20 days before the earthquake. A comparison of data over the epicenter and those over its reference area can be employed to discriminate the earthquake-related anomalies from global effects. Results prove that anomalous enhancements of $N_{\mathrm{e}}, N_{\mathrm{i}}$, and $T_{\mathrm{i}}$ occur specifically around the epicenter area. The intersection of the temporal and spatial results confirms that $N_{\mathrm{e}}$ and $N_{\mathrm{i}}$ are useful and sensitive detecting anomalous related to the $2010 M=8.8$ Chile earthquake.
\end{abstract}

\section{Introduction}

Seismo-ionospheric anomalies have been intensively investigated (e.g., Hayakawa and Fujinawa, 1994; Hayakawa, 1999; Hayakawa and Molchanov, 2002; Pulinets and Boyarchuk, 2004; Molchanov and Hayakawa, 2008). Liu et al. (2000,
2001, 2004, 2006, 2009, 2010, 2011) reported the electron density in terms of the ionospheric F2-peak plasma frequency $f o F 2$ and the total electron content (TEC) frequently and significantly decrease or increase 1-6 days before large earthquakes by using a median base analysis that consists of the running median of the previous 1-15 day observation and associated lower/upper quantile. On the other hand, Oyama et al. (2008) examined data of Hinotori satellite and found ionospheric electron temperatures around the epicenters significantly decreased in the afternoon periods within 5 days before and after 3 earthquakes: 22 November $1981 M=6.6$, 11 January $1982 M=7.4$ and 11 January $1982 M=6.6$ earthquakes over the Philippines. More recently, Oyama et al. (2011) analyzed the ionospheric responses during the $1981 M=7.5$ Chile earthquake by means of the DE- 2 satellite and observed a minimum of the $\mathrm{O}^{+}$ion density near the epicenter developing 5 days before the earthquake. However, opposite to the decrease anomalies reported by Oyama et al. (2011), Píša et al. (2011) observed an anomalous increase of the $\mathrm{O}^{+}$ion density by DEMETER/IAP over the epicenter area 10-20 days before the 27 February $2010 M=8.8$ Chile earthquake.

It is known that whistlers are ELF/VLF waves, which often originate in the lightning discharges and propagate along the magnetic field lines. The whistler dispersion parameter is defined by the Eckersley law, $D=t f^{1 / 2}$ (Helliwell, 1965), where $t$ is the time delay and the $f$ is the wave frequency. In general, whistlers with high dispersion come from the 
(a) Before the Chile earthquake

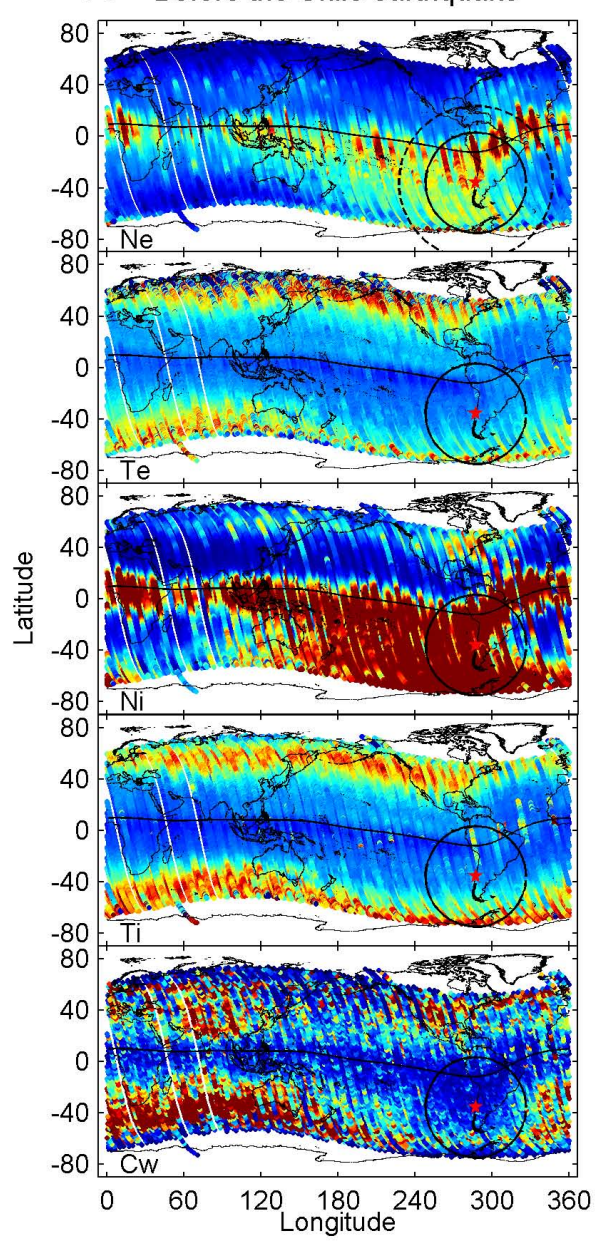

(b) After the Chile earthquake

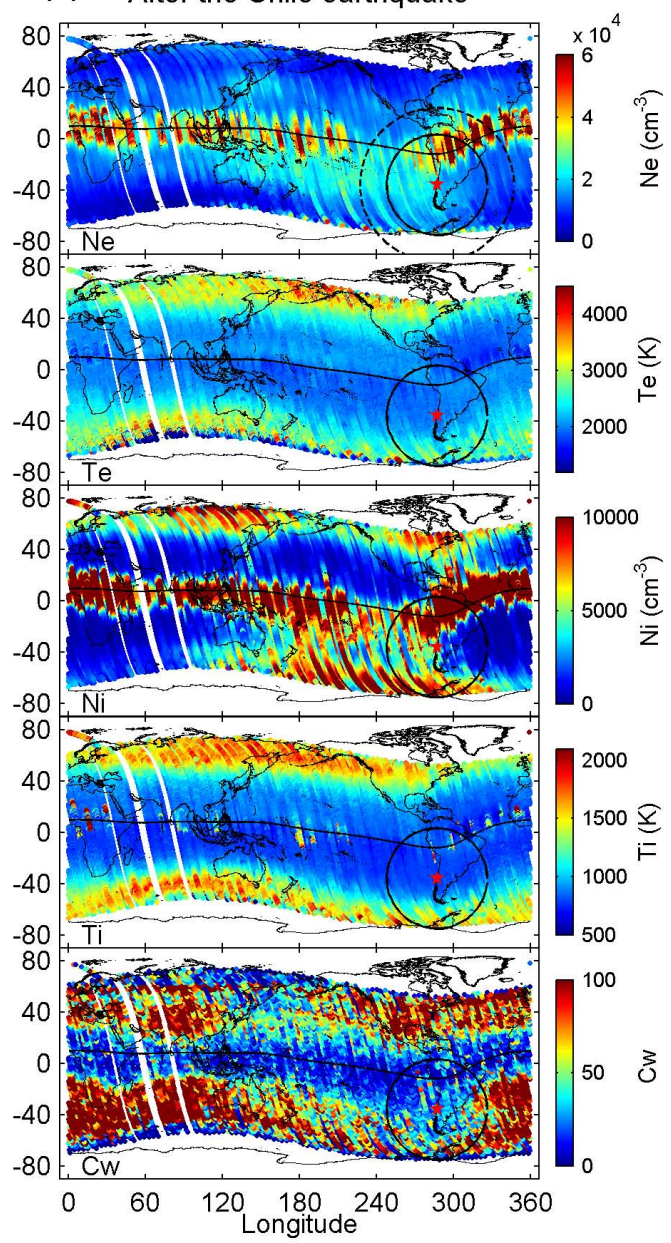

Fig. 1. The global distribution of $N_{\mathrm{e}}, T_{\mathrm{e}}, N_{\mathrm{i}}, T_{\mathrm{i}}$, and $C_{\mathrm{w}}$ 10-20 days (a) before and (b) after the Chile earthquake (from top to below). The red star denotes the epicenter. The black curve is the geomagnetic equator. The dashed and solid circles represent the earthquake preparation area and the reduced analyzing region, respectively.

Table 1. Ionospheric parameters near the Chile earthquake.

\begin{tabular}{lllllll}
\hline & $N_{\mathrm{e}}$ & $T_{\mathrm{e}}$ & $N_{\mathrm{i}}$ & $T_{\mathrm{i}}$ & $C_{\mathrm{w}}$ \\
\hline \multirow{3}{*}{ before } & upper quartile & 34866.30 & 2344.80 & 18982.30 & 1114.58 & 29 \\
& median & 28737.80 & 2113.39 & 13413.70 & 920.55 & 16 \\
& lower quartile & 23371.65 & 1969.64 & 8076.93 & 843.03 & 8 \\
\hline \multirow{3}{*}{ after } & upper quartile & 23993.50 & 2251.10 & 7984.22 & 985.738 & 50 \\
& median & 19249.20 & 2069.13 & 4892.11 & 830.66 & 29 \\
& lower quartile & 15839.20 & 1967.39 & 2197.16 & 784.837 & 17 \\
\hline
\end{tabular}

opposite hemisphere or are due to whistlers going several times back and forth in the magnetosphere (Hayakawa et al., 1993; Elie et al., 1999). In fact, ELF and VLF waves are related not only to lightning but also to earthquakes (Pulinets and Boyarchuk, 2004; Athanasiou et al., 2011; Sidiropoulos et al., 2011; Anagnostopoulos et al., 2012). Hayakawa et al. (1993) statistically examined whistlers at low latitudes and found that whistlers with anomalous dispersions are likely to be closely correlated with $M=6.0$ earthquakes. Due to the waves and particle interaction, energetic particles precipitate from the magnetosphere and result in the associated flux increase in the ionosphere, which can be considered as a seismic precursor (Boskova et al., 1994; Battiston, 2012). 
Table 2. Difference of ionospheric parameters before and after the Chile earthquake.

\begin{tabular}{lllllll}
\hline & $\Delta N_{\mathrm{e}}$ & $\Delta T_{\mathrm{e}}$ & $\Delta N_{\mathrm{i}}$ & $\Delta T_{\mathrm{i}}$ & $\Delta C_{\mathrm{W}}$ \\
\hline \multirow{4}{*}{ EQK region } & upper quartile & 13680.56 & 168.46 & 12205.30 & 180.24 & -2 \\
& median & 8302.34 & 48.36 & 7632.02 & 97.30 & -15 \\
& lower quartile & 3794.24 & -52.15 & 3203.61 & 32.89 & -32 \\
\hline \multirow{3}{*}{ Ref region } & upper quartile & 4317.15 & 62.39 & 5008.26 & 90.653 & 12.25 \\
& median & 436.93 & -33.28 & 2535.99 & 29.77 & -8 \\
& lower quartile & -4643.26 & -130.07 & 41.31 & -48.27 & -43 \\
\hline
\end{tabular}

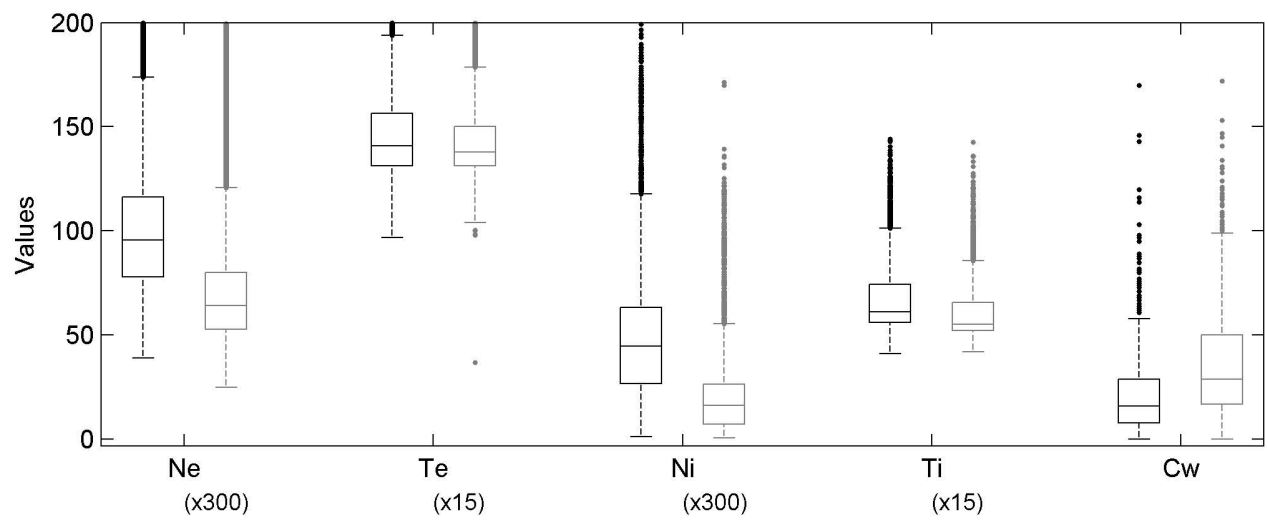

Fig. 2. The statistical analysis of the parameters, $N_{\mathrm{e}}, T_{\mathrm{e}}, N_{\mathrm{i}}, T_{\mathrm{i}}$, and $C_{\mathrm{W}}$, in the epicenter region before and after the Chile earthquake. The black and gray boxes denote data observed before and after the Chile earthquake, respectively. Each parameter has been factorized to fit into the figure (the factor is denoted under the $x$ axis).

DEMETER satellite is a micro-satellite that observes the region within $65^{\circ}$ geomagnetic latitude in a $680 \mathrm{~km}$ altitude, $98.3^{\circ}$ inclination orbit. It is a sun-synchronous satellite and passes at almost the same local time everywhere at 10:30 and 22:30 LT. It was launched in June 2004 and stopped in December 2010. Its main scientific objectives are the detection and characterization of ionosphere electrical and magnetic disturbances in connection with seismic activity (Cussac et al., 2006). DEMETER carries 6 payloads: IAP (Instrument d'Analyse du Plasma) detecting the plasma density and the ion composition (Berthelier et al., 2006); ISL (Instrument Sonde de Langmuir) measuring the electron density and temperature (Lebreton et al., 2006); RNF (Réseau de Neurones Formel) performing an automatic identification and classification of the whistlers from ELF-VLF electric field measurements (Elie et al., 1999), and ICE (Instrument Champ Electrique), IMSC (Instrument Magnetic Search Coil), and IDP (Instrument for the Detection of Particle) recording the electric field, magnetic field, and high energy particles, respectively. Píša et al. (2011) reported the $\mathrm{O}^{+}$ion density around the epicenter remarkably increased 10-20 days before the 27 February $2010 M=8.8$ Chile earthquake. In this paper, we extend their study utilizing the first 3 payloads temporally and spatially examining the electron density, electron temperature, $\mathrm{O}^{+}$ion density, ion temperature, and whistler counts simultaneously recorded by DEMETER during the $M=8.8$ Chile earthquake.

\section{Observation}

A magnitude 8.8 earthquake occurred in Chile $\left(35.90^{\circ} \mathrm{S}\right.$, $287.27^{\circ}$ E geographic; $25.74^{\circ} \mathrm{S}, 359.5^{\circ}$ E geomagnetic) with $35 \mathrm{~km}$ depth at 06:34 UT (Universal Time) on 27 February 2010. Píša et al. (2011) found no obvious anomaly can be detected on the daytime orbits (the local morning hours), but the $\mathrm{O}^{+}$ion density $N_{\mathrm{i}}$ of the nighttime orbit significantly increased 10-20 days before the earthquake. Here we also focus on the nighttime DEMETER parameters. Figure 1 illustrates global distributions of the electron density $N_{\mathrm{e}}$, electron temperature $T_{\mathrm{e}}, \mathrm{O}^{+}$ion density $N_{\mathrm{i}}$, ion temperature $T_{\mathrm{i}}$, and whistler counts $C_{\mathrm{w}}$ (for detailed definition, see Elie et al., 1999) within 10-20 day before and after the earthquake. It is found that, around the epicenter, $N_{\mathrm{e}}, N_{\mathrm{i}}$ and $T_{\mathrm{i}}\left(C_{\mathrm{W}}\right)$ remarkably increase (decreases) 10-20 days before the earthquake, while $T_{\mathrm{e}}$ yields no obvious changes.

We quantitatively examine changes of the above parameters around the epicenter before and after the earthquake. Dobrovolsky et al. (1979) suggested that in the lithosphere the earthquake preparation area can be estimated by $R=10^{0.43} \mathrm{M}$, where $R$ is the radius of the earthquake preparation zone from the epicenter and $M$ is the 


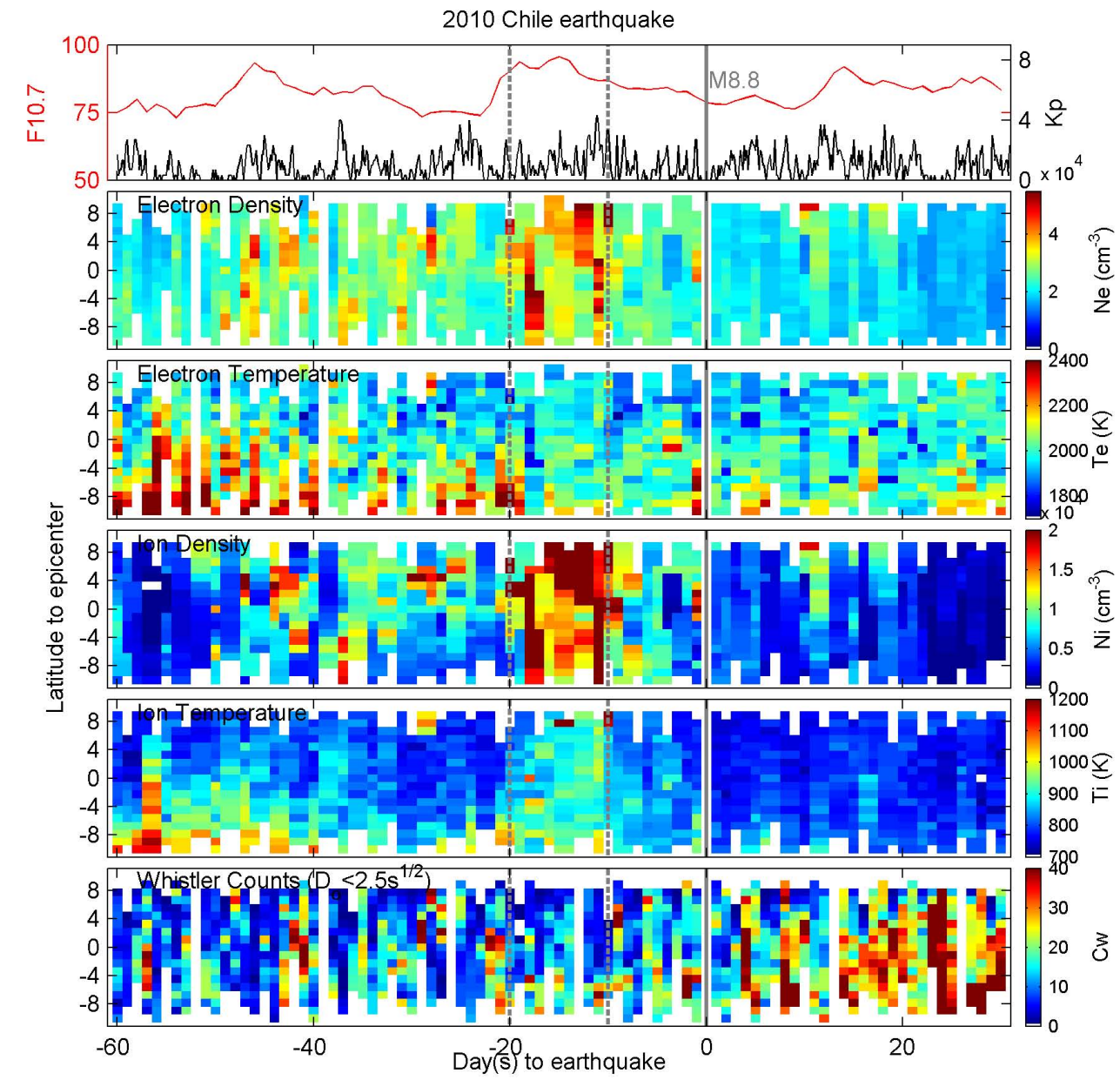

Fig. 3. The temporal variations of $\mathrm{F} 10.7, K_{p}$ index (the first panel) and observations of the nearest orbit passing over the epicenter in a $20^{\circ}$ latitudinal range by DEMETER 60 days before and 30 days after the Chile earthquake. From the second to the sixth panels are $N_{\mathrm{e}}, T_{\mathrm{e}}, N_{\mathrm{i}}, T_{\mathrm{i}}$ and $C_{\mathrm{W}}$, respectively. The vertical line denotes the earthquake day, and the dashed line denotes 20 and 10 days before the earthquake.

forthcoming earthquake magnitude. For the $M=8.8$ Chile earthquake, we obtain $R=6081 \mathrm{~km}$. However, DEMETER observes the area below $65^{\circ}$ invariant latitude. To avoid exceeding the observed latitude and to remove the data in the sub-auroral zone, an analysis radius $\mathrm{Ra}=3926 \mathrm{~km}$ has been given instead (the solid circle in Fig. 1). We first statistically investigate anomalies of each parameter with box-andwhisker (box) plots (Wilcox, 2010) within the Ra radius from the epicenter 10-20 days before (Fig. 1a) and after (Fig. 1b) the earthquake. The lower (upper) quartile is the number such that at least $25 \%(75 \%)$ of the sorted observations are less (greater) than or equal to it. In the plot, the ends of a box are the upper and lower quartiles. The horizontal line in the box denotes the statistical median. The dots are the outliers that exceed 1.5 times the interquartile range from the end of the box and are unusually small or large. The lines extending out from the box are called whiskers. The ends of the whiskers mark the smallest and largest values that are not outliers. When one median (i.e., horizontal line) does not overlap with the other's upper and lower quartiles (i.e., box), the two are declared to be significantly different. Figure 2 reveals that around the epicenter $N_{\mathrm{e}}$ and $N_{\mathrm{i}}$ significantly increase; however, $C_{\mathrm{w}}$ significantly decreases $10-20$ days before the earthquake (details are shown in Table 1). Although $N_{\mathrm{e}}, N_{\mathrm{i}}$, and $C_{\mathrm{w}}$ anomalous around the epicenter are statistically significant, they still cannot be confirmed to be earthquake-related, because global effects, such as solar radiations, solar winds, magnetic storms, neutral winds, etc., could result in similar anomalies. To discriminate the global and earthquake (local) effects, we have to conduct either a temporal study by examining data over the epicenter in various years, like the approach of Píša et al. (2011), or a spatial study by comparing data over the epicenter with those of a reference area, which usually is far from the epicenter but with the same magnetic latitude.

For the temporal study, Píša et al. (2011) performed a statistical analysis with $N_{\mathrm{i}}$ in the vicinity of the epicenter in the first 3 months of the years $2007-2010$ and observed a 


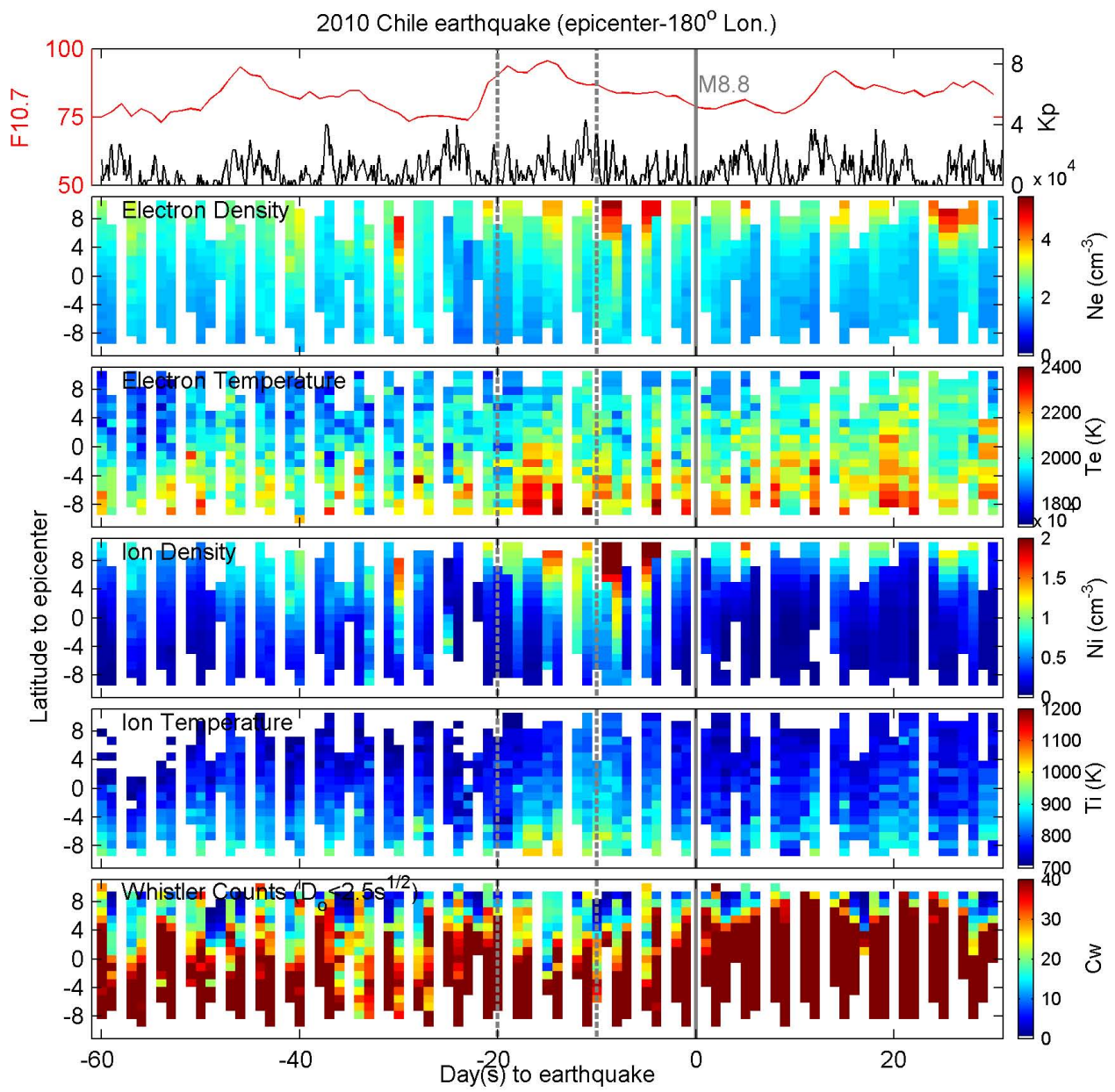

Fig. 4. Similar to Fig. 3, the parameters observed along the reference longitude, $108^{\circ} \mathrm{E}$.

large increase 10-20 days before the main shock. To crosscompare with $N_{\mathrm{i}}$ reported by Píša et al. (2011), we simultaneous examine $N_{\mathrm{e}}, T_{\mathrm{e}}, N_{\mathrm{i}}, T_{\mathrm{i}}$, and $C_{\mathrm{w}}$ along the orbit near the epicenter within a latitudinal range of $10^{\circ}$ from the epicenter 60 days before to 30 days after the earthquake. Figure 3 displays a comparison of the overall study period. The geomagnetic index $K_{p}<5$ and solar flux in $10.7 \mathrm{~cm}$ (Lean, 1991) F10.7 $\leq 95.5$ reveal that the geomagnetic and solar activities are in a relatively quiet condition during this period. However, it still can be noticed that there is a F10.7 increase during 10-20 and 40-50 days before the earthquake. $N_{\mathrm{e}}$ and $N_{\mathrm{i}}$ significantly increase 10-20 days before and slightly increase $40-50$ days before the earthquake. Note that the time period of 40-50 days before the earthquake is much earlier than the lead time of 18-26 days of the statistical result reached by $79 M \geq 6.0$ earthquakes in the Chile area during 1999 2011 (Ho et al., 2013), and therefore we mainly focus on the period 10-20 days before the earthquake. $T_{\mathrm{e}}$ 10-20 days before the earthquake is slightly cooler than $40-60$ days before. However, comparing observations after the earthquake, it yields no clear anomalies. We also examine the whistler of dispersion $1\left(D<2.5 \mathrm{~s}^{1 / 2}\right)$ and find no obvious anomalies in $C_{\mathrm{w}}$ 10-20 days before the earthquake.

Figure 3 displays that $N_{\mathrm{e}}$ and $N_{\mathrm{i}}$ yield the greatest values 10-20 days before the earthquake; $C_{\mathrm{w}}$ greatly increases 10-20 days after the earthquake; $T_{\mathrm{e}}$ reaches the greatest values 40-60 days before; and $T_{\mathrm{i}}$ slightly increases 10-20 days before. The above complexities suggest that a sole/simple temporal study is very difficult to identify seismo-electric anomalies. To confirm the anomalies, we further examine the parameters away from the epicenter. Here, to avoid possible contamination of earthquakes and to conduct a sensible comparison, we take an area far away from the epicenter but at the same geomagnetic latitude as the reference, which centers at $13^{\circ} \mathrm{S}, 108^{\circ} \mathrm{E}$. To conduct a comprehensive investigation, we also examine the parameters at a mid-location between the epicenter and the reference, which centers at $21^{\circ} \mathrm{S}, 193^{\circ} \mathrm{E}$. Figure 4 reveals no significant anomalies in $N_{\mathrm{i}}$ and $N_{\mathrm{e}}$, while Fig. 5 depicts that $N_{\mathrm{e}}$ and $N_{\mathrm{i}}$ yield large values 10-14 days before the earthquake. The two figures display that $C_{\mathrm{w}}$ generally increases, and $T_{\mathrm{e}}$ and $T_{\mathrm{i}}$ remain at similar values during the whole observation. The significant differences between 


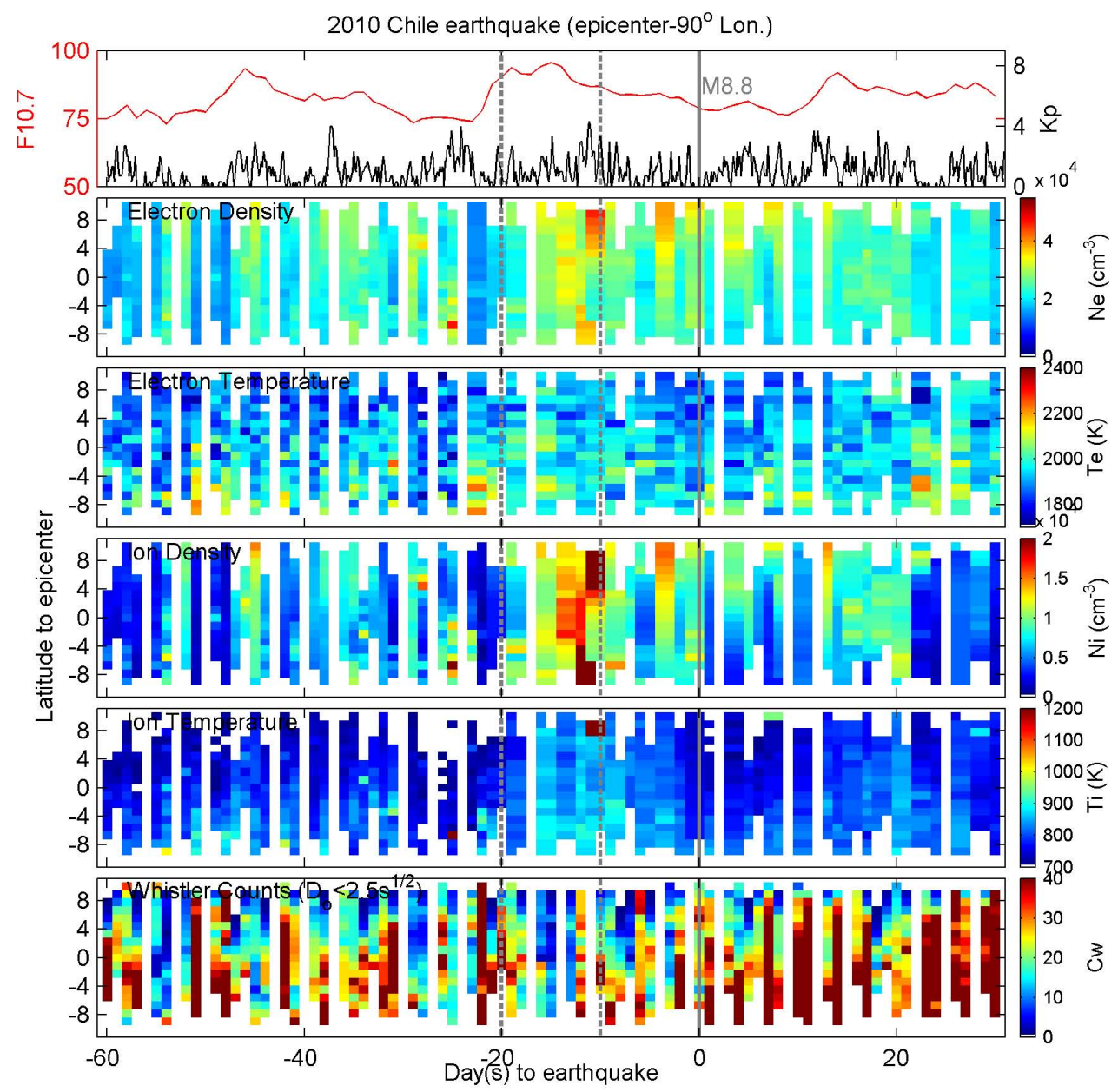

Fig. 5. Similar to Fig. 3, the parameters observed between the epicenter and the reference longitude, $193^{\circ} \mathrm{E}$.

Figs. 3 and 4 (or 5) indicate that the seismo-electric anomalies most likely appear over the epicenter region.

To discriminate the global or local effects, we conduct a spatial analysis by cross-comparing each parameter observed over the epicenter region with that at the reference area centering at $13^{\circ} \mathrm{S}, 108^{\circ} \mathrm{E}$ within 10-20 days before and after the earthquake. The analysis radius at the epicenter and that at the reference center should be identical to have sensible cross-comparisons. We first compute the difference of each parameter $\Delta N_{\mathrm{e}}, \Delta N_{\mathrm{i}}, \Delta T_{\mathrm{e}}, \Delta T_{\mathrm{i}}$, and $\Delta C_{\mathrm{w}}$ between 1020 days before and after (for example, Fig. 1a minus $1 \mathrm{~b}$ obtaining Fig. 6, accordingly). Figure 6 reveals that $\Delta N_{\mathrm{e}}$ and $\Delta N_{\mathrm{i}}\left(\Delta C_{\mathrm{w}}\right)$ in the epicenter area are greater (is less) than those (that) in the reference region. However, $\Delta T_{\mathrm{e}}$ and $\Delta T_{\mathrm{i}}$ in the conjugate of the epicenter enhance. We further statistically investigate the differences of each parameter in the epicenter and the reference area between 10-20 days before and after the earthquake. Figure 7 reveals that anomalies of $\Delta N_{\mathrm{e}}, \Delta N_{\mathrm{i}}$, and $\Delta T_{\mathrm{i}}$ in the epicenter area are significantly greater than those in the reference (details are in Table 2).

\section{Discussion and conclusion}

Research shows that seismo-ionospheric anomalies of GPS TEC appear 1-6 days before large earthquakes (Liu et al., 2000, 2001, 2004, 2006; Chen et al., 2004; Akhoondzadeh et al., 2010a, b; Le et al., 2011). However, it can be seen that the seismo-electric anomalies of DEMETER appear 10-20 days before the $M=8.8$ Chile earthquake observed in this study and that of Píša et al. (2011), which is much earlier than that reported by previous research. Ho et al. (2013) statistically examine occurrence proportions of the GPS TEC anomalies associated with $79 M=6.0$ earthquakes in the Chile area during 1999-2011. They find that anomalous increases of the GPS TEC most likely appear 18-26 days before the earthquakes in the Chile area, which generally agrees with the increase anomalies in $N_{\mathrm{i}}$ and $N_{\mathrm{e}}$ appearing 10-20 days before the Chile earthquake observed in this paper. Although the causes of the long lead time of seismo-electric anomalies are not fully understood, the underground structure/property and focal mechanism should play important roles. 


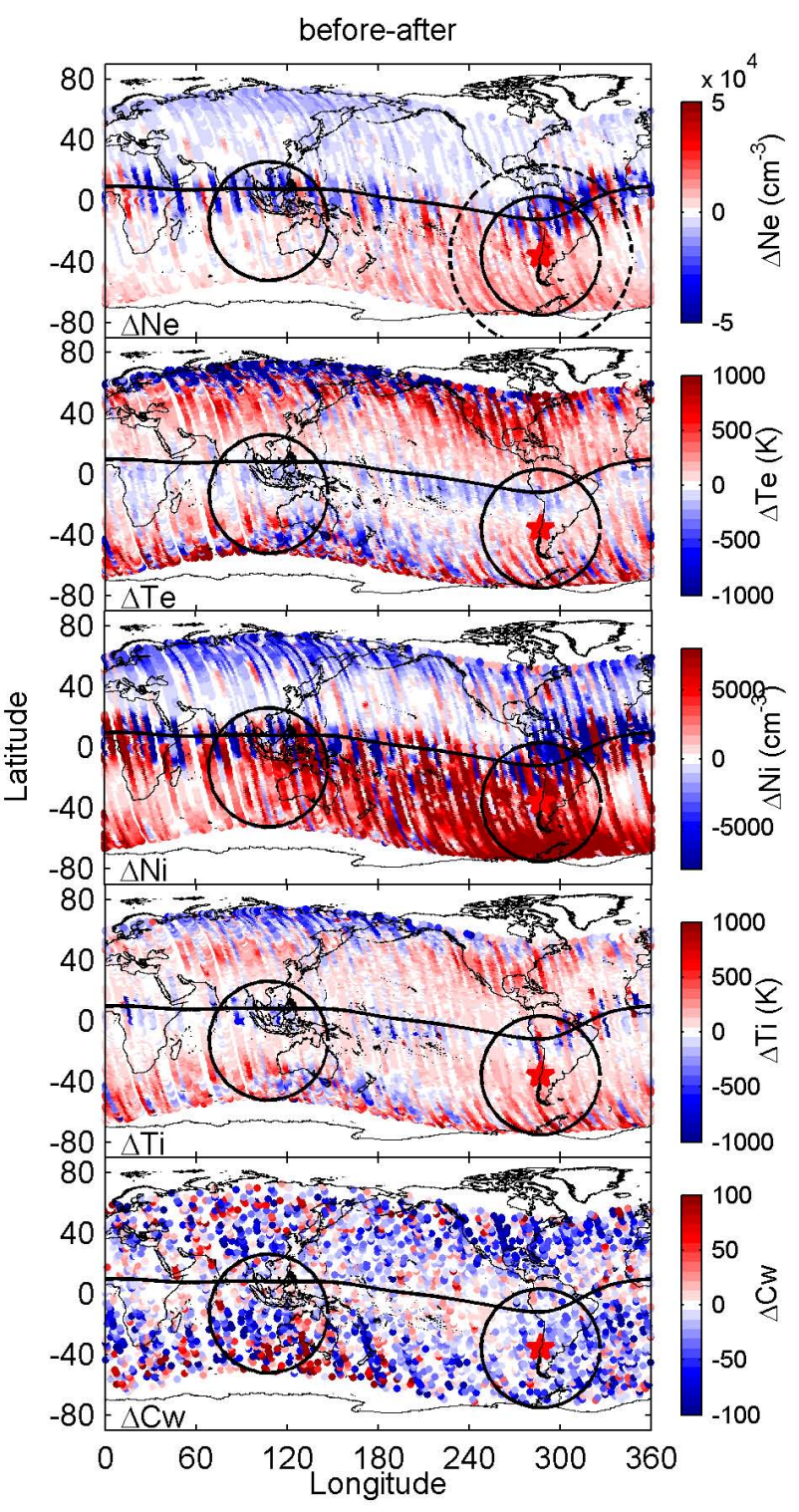

Fig. 6. The differences of each parameter between 10-20 days before and after the Chile earthquake. The red star and black line denote the epicenter and the geomagnetic equator, respectively. The dashed line circle is the earthquake preparation zone, and the solid line circles are the reduced analyzing region in the epicenter and reference point.

Sarkar et al. (2012) observed that $N_{\mathrm{e}}$ and $T_{\mathrm{e}}$ of DEMETER concurrently increased around the epicenter 1 day before the $2010 M=7.0$ Haiti earthquake. Oyama et al. (2008) reported that $T_{\mathrm{e}}$ of the Hinotori satellite decreased around the epicenters within 5 days before and after the three $M=6.6$ earthquakes during 1981-1982. Akhoondzadeh et al. (2010a, b) found that $T_{\mathrm{e}}$ of DEMETER decreased 4 days before but increased 2 days before the $2009 M=8.1$ Samoa earthquake. Various leading days/times and complex polarities (i.e., increase or decrease) suggest causal mechanisms of the
$T_{\mathrm{i}}$ and $T_{\mathrm{e}}$ anomalies to be very complex. The results in this paper show that the $T_{\mathrm{e}}$ anomaly is insignificant while the $T_{\mathrm{i}}$ anomaly is marginally significant. Nevertheless, the anomalies of $T_{\mathrm{i}}$ and $T_{\mathrm{e}}$ are less significant than those of $N_{\mathrm{i}}$ and $N_{\mathrm{e}}$. Scientists report that $T_{\mathrm{e}}$ in the ionosphere is determined by the heat balance between the heating by photoelectrons, cooling through Coulomb collisions with ions, and heat conduction along the magnetic field lines (cf. Kakinami et al., 2011). Schunk and Nagy (1978) showed that the rapid energy transfer from the electrons to the ions and from the ions to the neutrals results in small temperature differences between electrons, ions, and neutrals. Both positive and negative correlations between the $N_{\mathrm{e}}$ and $T_{\mathrm{e}}$ have been reported. Kakinami et al. (2011) reported that the U-shaped relation includes a negative correlation for lower values of $N_{\mathrm{e}}$ and a positive correlation for higher values of $N_{\mathrm{e}}$. They showed that after about 20:00 LT, both $N_{\mathrm{e}}$ and $T_{\mathrm{e}}$ follow the usual nighttime decay until sunrise and a positive correlation between $N_{\mathrm{e}}$ and $T_{\mathrm{e}}$ is detected. Their U-shaped relation at 20:00-22:00 LT and 22:00-24:00 LT further reveals that, although there was a positive correlation, a large amount of $N_{\mathrm{e}}$ increase can simply cause a small amount of $T_{\mathrm{e}}$ increase. This might explain the insignificance of the $T_{\mathrm{e}}$ anomalies.

Figure 3 reveals that the area of significant $N_{\mathrm{i}}\left(N_{\mathrm{e}}\right)$ changes goes from Australia to Chile covering the whole southern Pacific 10-20 days before the Chile earthquake, which seems to suggest the earthquake preparation area being vast. Note that the vast area is partially overlapped in the Weddell Sea area where the nighttime $N_{\mathrm{e}}$ is significantly greater than the daytime one in summer in the Southern Hemisphere (Lin et al., 2010). Thus, the seismo- $N_{\mathrm{e}}$ anomalies in the vast area could be contaminated by the Weddell Sea anomaly.

Liu et al. (2013) statistically studied low-latitude whistlers and $20 M=5.0$ earthquakes in Taiwan, and found the whistlers around the epicenters significantly decrease before the earthquakes. They suggested that whistlers depart from the earthquake preparation area, which results in whistlers significantly decreasing around the epicenter. Although it is not statistically significant, the whistlers tend to reduce over the epicenter (Figs. 1, 2, and 4; Table 1), which generally agrees with Liu et al. (2013).

Anagnostopoulos and Papandreou (2012) reported possible links between space condition and large earthquakes. Therefore, to identify seismo-electric anomalies, it is essential to discriminate between global and local effects. It is known that earthquake-related anomalies are local effects, while solar radiations, solar winds, magnetic storms, neutral winds, etc. can trigger anomalies all over the world, which are generally termed global effects. The observations over the epicenter area and those over its reference shall simultaneously experience the same global effects. The box-andwhisker method is applied to discriminate the earthquakerelated effects from the global ones. Figures 6 and 7 show 


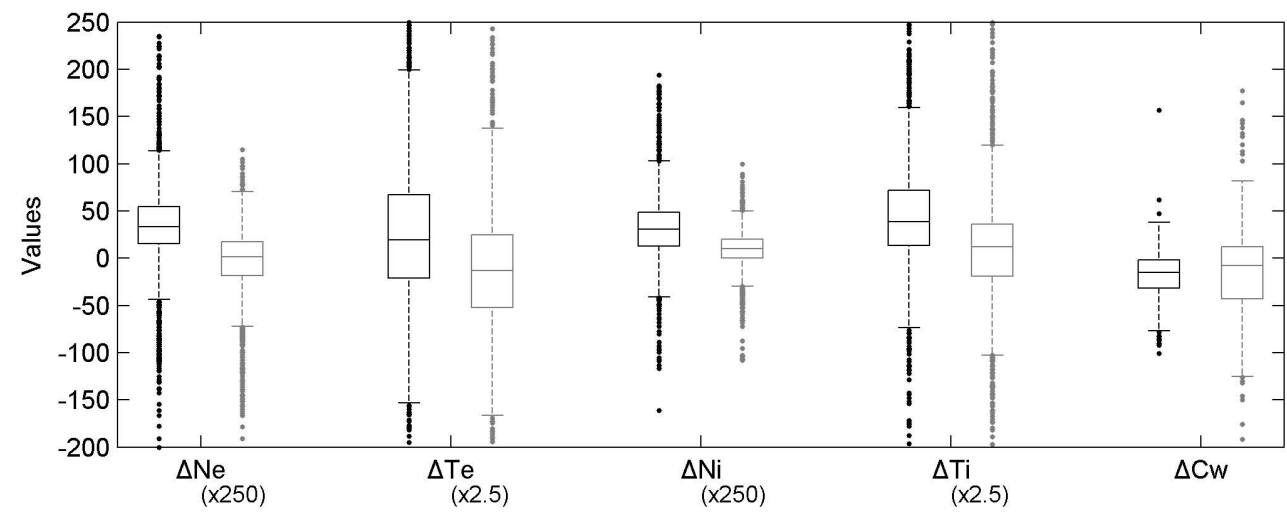

Fig. 7. The statistical analysis on the differences at the epicenter and reference region before and after the Chile earthquake. The black and gray boxes denote data observed in the epicenter and reference region (i.e., $180^{\circ}$ longitude shifting), respectively.

that the $N_{\mathrm{e}}, N_{\mathrm{i}}$, and $T_{\mathrm{i}}$ anomalies are very likely related to the $M=8.8$ Chile earthquake.

In conclusion, to discriminate global and local effects, both temporal and spatial analyses are required. Temporal analysis is useful to monitor and detect anomalies at a certain area, while spatial analysis is essential to confirm the detected temporal anomalies related to the local effect (possibly a forthcoming earthquake). Results in this study demonstrate that the $N_{\mathrm{i}}$ and $N_{\mathrm{e}}$ anomalies are statistically significant, which are most likely the seismo-electric anomalies appearing before the $2010 M=8.8$ Chile earthquake.

Acknowledgements. This work was partially supported by the National Science Council with National Central University grant NSC-101-2628-M-008-003.

\section{Edited by: S. Tinti}

Reviewed by: A. Anastasiadis, G. C. Anagnostopoulos, and one anonymous referee

\section{References}

Akhoondzadeh, M., Parrot, M., and Saradjian, M. R.: Electron and ion density variations before strong earthquakes $(M>6.0)$ using DEMETER and GPS data, Nat. Hazards Earth Syst. Sci., 10, $7-$ 18, doi:10.5194/nhess-10-7-2010, 2010a.

Akhoondzadeh, M., Parrot, M., and Saradjian, M. R.: Investigation of VLF and HF waves showing seismo-ionospheric anomalies induced by the 29 September 2009 Samoa earthquake $\left(M_{\mathrm{W}}=8.1\right)$, Nat. Hazards Earth Syst. Sci., 10, 1061-1067, doi:10.5194/nhess-10-1061-2010, 2010b.

Anagnostopoulos, G. and Papandreou, A.: Space conditions during a month of a sequence of six $M>6.8$. earthquakes ending with the tsunami of 26 December 2004, Nat. Hazards Earth Syst. Sci., 12, 1551-1559, doi:10.5194/nhess-12-1551-2012, 2012.

Athanasiou, M. A., Anagnostopoulos, G. C., Iliopoulos, A. C., Pavlos, G. P., and David, C. N.: Enhanced ULF radiation observed by DEMETER two months around the strong 2010
Haiti earthquake, Nat. Hazards Earth Syst. Sci., 11, 1091-1098, doi:10.5194/nhess-11-1091-2011, 2011.

Battiston, R.: Magnetosphere-litosphere correlations using NOAA electron data, Earthquakes Early Warning from Space, EriceSicily, Italy, 21-24 October, 2012.

Berthelier, J., Godefroy, M., Leblanc, F., Seran, E., Peschard, D., Gilbert, P., and Artru, J.: IAP, the thermal plasma analyzer on DEMETER, Planet. Space. Sci., 54, 487-501, 2006.

Boskova J., Smilauer, J., Triska, P., and Kudela, K.: Anomalous behaviour of plasma 14 parameters as observed by the intercosmos 24 satellite prior to the Iranian 15 earthquake of 20 June 1990, Studia geoph. et geod., 38, 213, 1994.

Chen, Y.-I., Liu, J.-Y., Tsai, Y.-B., and Chen, C.-S.: Statistical Tests for Pre-earthquake Ionospheric Anomaly, Terr. Atmos. Ocean. Sci. 15, 385-396, 2004.

Cussac, T., Clair, M., Ultre-Guerard, P., Buisson, F., Lassalle-Balier, G., Ledu, M., Elisabelar, C., Passot, X., and Rey, E.: The Demeter microsatellite and ground segment, Planet. Space. Sci., 54, 413427, 2006.

Dobrovolsky, I. P., Zubkov, S. I., and Miachkin, V. I.: Estimation of the size of earthquake preparation zones, Pure. Appl. Geophys., 117, 1025-1044, 1979.

Elie, F., Hayakawa, M., Parrot, M., Pinçon, J.-L., and Lefeuvre, F.: Neural network system for the analysis of transient phenomena on board the DEMETER micro-satellite, IEICE Trans. Fundam. Electron. Commun. Comput. Sci., E82-A(8), 1575-1581, 1999.

Hayakawa, M.: Atmospheric and Ionospheric Electromagnetic Phenomena with Earthquakes, Terra Scientific, Tokyo, Japan, 1-996, 1999.

Hayakawa, M. and Fujinawa, Y.: Electromagnetic Phenomena Related to Earthquake Predication, Terra Scientific, Tokyo, Japan, 1-677, 1994.

Hayakawa, M. and Molchanov, O. A.: Seismo Electromagnetics: Lithosphere-Atmosphere-Ionosphere Coupling, Terra Scientific, Tokyo, Japan, 1-477, 2002.

Hayakawa, M., Yoshino, T., and Morgounov, V. A.: On the possible influence of seismic activity on the propagation of magnetospheric whistlers at low latitudes, Phys. Earth. Planet. In., 77, 97-108, 1993.

Helliwell, R. A.: Whistlers and Related Ionospheric Phenomena, Stanford University, Stanford, USA, 1-349, 1965. 
Ho, Y. Y., Jhuang, H. K., Su, Y. C., and Liu, J. Y.: Seismoionospheric anomalies in total electron content of the GIM and electron density of DEMETER before the 27 February 2010 $M=8.8$ Chile earthquake, J. Adv. Space Res., http://dx.doi.org/ 10.1016/j.asr.2013.02.006, 2013.

Kakinami, Y., Watanabe, S., Liu, J. Y., and Balan, N.: Correlation between electron density and temperature in the topside ionosphere, J. Geophys. Res., 116, A12331, doi:10.1029/2011JA016905, 2011.

Le, H., Liu, J. Y., and Liu, L.: A statistical analysis of ionospheric anomalies before 736 M6.0+ earthquakes during 2002-2010, J. Geophys. Res., 116, A02303, doi:10.1029/2010JA015781, 2011.

Lean, J.: Variations in the Sun's radiative output, Rev. Geophys., 29, 505-535, 1991.

Lebreton, J.-P., Stverak, S., Travnicek, P., Maksimovic, M., Klinge, D., Merikallio, S., Lagoutte, D., Poirier, B., Blelly, P.-L., Kozacek, Z., and Salaquarda, M.: The ISL Langmuir probe experiment processing onboard DEMETER: Scientific objectives, description and first results, Planet. Space. Sci., 54, 472-486, 2006.

Lin, C. H., Liu, C. H., Liu, J. Y., Chen, C. H., Burns, A. G., and Wang, W.: Mid-latitude summer nighttime anomaly of the ionospheric electron density observed by FORMOSAT?3/COSMIC, J. Geophys. Res., 115, A03308, doi:10.1029/2009JA014084, 2010.

Liu, J. Y., Chen, Y. I., Pulinets, S. A., Tsai, Y. B., and Chuo, Y. J.: Seismo-ionospheric signatures prior to M 6.0 Taiwan earthquakes, Geophys. Res. Lett., 27, 3113-3116, 2000.

Liu, J. Y., Chen, Y. I., Chuo, Y. J., and Tsai, H. F.: Variations of ionospheric total electron content during the Chi-Chi Earthquake, Geophy. Res. Lett., 28, 1383-1386, 2001.

Liu, J. Y., Chuo, Y. J., Shan, S. J., Tsai, Y. B., Chen, Y. I., Pulinets, S. A., and Yu, S. B.: Pre-earthquake ionospheric anomalies registered by continuous GPS TEC measurements, Ann. Geophys., 22, 1585-1593, doi:10.5194/angeo-22-1585-2004, 2004.

Liu, J. Y., Chen, Y. I., Chuo, Y. J., and Chen, C. S.: A statistical investigation of pre-earthquake ionospheric anomaly, J. Geophys. Res., 111, A05304, doi:10.1029/2005JA011333, 2006.

Liu, J. Y., Chen, Y. I., Chen, C. H., Liu, C. Y., Chen, C. Y., Nishihashi, M., Li, J. Z., Xia, Y. Q., Oyama, K.-I., Hattori, K., and Lin, C. H.: Seismo-ionospheric GPSTEC anomalies observed before the 12 May 2008 Mw7.9 Wenchuan Earthquake, J. Geophys. Res., 114, A04320, doi:10.1029/2008JA013698, 2009.

Liu, J. Y., Chen, Y. I., Chen, C. H., and Hattori, K.: Temporal and spatial precursors in the ionospheric global positioning system (GPS) total electron content observed before the 26 December 2004 M9.3 Sumatra-Andaman Earthquake, J. Geophys. Res., 115, A09312, doi:10.1029/2010JA015313, 2010.
Liu, J. Y., Le, H., Chen, Y. I., Chen, C. H., Liu, L., Wan, W., Su, Y. Z., Sun, Y. Y., Lin, C. H., and Chen, M. Q.: Observations and simulations of seismoionospheric GPS total electron content anomalies before the 12 January 2010 M7 Haiti earthquake, J. Geophys. Res., 116, A04302, doi:10.1029/2010JA015704, 2011.

Liu, J. Y., Wang, K., Chen, C. H., Yang, W. H., Yen, Y. H., Chen, Y. I., Hatorri, K., Su, H. T., Hsu, R. R., and Chang, C. H.: A statistical study on ELF-whistler/emissions and M5.0 earthquakes in Taiwan, J. Geophys. Res., doi:10.1002/jgra.50356, 2013.

Molchanov, O. A. and Hayakawa, M.: Seismo-Electromagnetics and Related Phenomena: History and Latest Results, Terra Scientific, Tokyo, Japan, 1-189, 2008.

Oyama, K.-I., Kakinami, Y., Liu, J. Y., Kamogawa, M., and Kodama, T.: Reduction of electron temperature in low-latitude ionosphere at $600 \mathrm{~km}$ before and after large earthquakes, J. Geophys. Res., 113, doi:10.1029/2008JA013367, 2008.

Oyama, K.-I., Kakinami, Y., Liu, J. Y., Abdu, M. A., and Cheng, C. Z.: Latitudinal distribution of anomalous ion density as a precursor of a large earthquake, J. Geophys. Res., 116, A04319, doi:10.1029/2010JA015948, 2011.

Píša, D., Parrot, M., and Santolík, O.: Ionospheric density variations recorded before the $2010 \mathrm{Mw} 8.8$ earthquake in Chile, J. Geophys. Res., 116, 1-8, doi:10.1029/2011JA016611, 2011.

Pulinets, S. and Boyarchuk, K.: Ionospheric Precursors of Earthquakes. Springer, New York, USA, 1-330, 2004.

Sarkar, S., Choudhary, S., Sonakia, A., Vishwakarma, A., and Gwal, A. K.: Ionospheric anomalies associated with the Haiti earthquake of 12 January 2010 observed by DEMETER satellite, Nat. Hazards Earth Syst. Sci., 12, 671-678, doi:10.5194/nhess-12671-2012, 2012.

Schunk, R. W. and Nagy, A. F.: Electron temperatures in the F region of the ionosphere: Theory and observations, Rev. Geophys. 16, 355-399, doi:10.1029/RG016i003p00355, 1978.

Sidiropoulos, N. F., Anagnostopoulos, G., and Rigas, V.: Comparative study on earthquake and ground based transmitter induced radiation belt electron precipitation at middle latitudes, Nat. Hazards Earth Syst. Sci., 11, 1901-1913, doi:10.5194/nhess-111901-2011, 2011.

Wilcox, R. R.: Fundamentals of modern statistical methods: substantially improving power and accuracy, Springer, New York, USA, 34-35, 2010. 